\title{
I Salão de Arte Infantil: apontamentos do crítico de arte José Geraldo Vieira sobre a expressão artística da criança (1961)
}

\section{The I Salon of Children's Art: appointments on the child's artistic expression by the art critic José Geraldo Vieira (1961)}

\author{
Dulce Regina Baggio Osinski*
}

\begin{abstract}
RESUMO
Este estudo analisará os artigos de autoria do escritor, crítico literário e crítico de arte José Geraldo Vieira (1897-1977), publicados no jornal Folha de São Paulo em 1961, por ocasião da realização da exposição de pinturas e desenhos de crianças que aconteceu na Galeria de Arte da Folha, como parte do I Salão de Arte Infantil, promovido por aquele jornal. O evento se inseria numa série de ações apoiadas em movimentos que defendiam a importância da livre-expressão artística da criança como parte de seu processo educacional e de desenvolvimento. Nesses textos, o autor tece considerações sobre as características da manifestação artística infantil, as quais serão colocadas em tensão com ideias sobre o tema que circulavam no período. Como fontes privilegiadas são utilizados artigos publicados na Folha de São Paulo e em outros jornais, como o Diário de Notícias e o Correio da Manhã.

Palavras-chave: I Salão de Arte Infantil. José Geraldo Vieira. Folha de São Paulo. Livre-expressão. Educação e arte.
\end{abstract}

\footnotetext{
ABSTRACT

This article analyzes the articles written by the writer, literary critic and art critic José Geraldo Vieira (1897-1977), published in the newspaper Folha de São Paulo in 1961, on the occasion of the exhibition of children's paintings and drawing that took place in the "Folha" Art Gallery as part of the I Salon of Children's Art, promoted by that newspaper. The event was part of

* Universidade Federal do Paraná, Programa de Pós-graduação em Educação. Curitiba, Paraná, Brasil. E-mail: dulceosinski@gmail.com. https://orcid.org/0000-0002-3506-4974.
} 
a series of actions supported by movements that defended the importance of children's free artistic expression as part of their educational and developmental process. In these texts, the author comments about the characteristics of the artistic manifestation of children which will be put in tension with ideas that circulated in the period about the theme. As privileged sources we used articles published in Folha de São Paulo and other newspapers, such as Diário de Notícias, and Correio da Manhã.

Keywords: I Salon of Children's Art. José Geraldo Vieira. Folha de São Paulo. Free-expression. Education and art.

\section{Introdução}

Em meados de 1961, a Galeria de Arte da Folha ${ }^{1}$ recebeu uma exposição que fugia dos padrões daquelas até então realizadas desde que fora criada, em 1957. Naquela ocasião, as pinturas e desenhos ali apresentados não haviam sido realizados por artistas com trajetórias já consolidadas ou em construção, mas por crianças em idade escolar, participantes do I Salão de Arte Infantil. Organizado pela Folha de São Paulo, o evento buscava se enquadrar na programação do Governo Federal, que decretara 1961 como o Ano da Criança, contando, em nível estadual, com o apoio da Secretaria de Educação de São Paulo. O empréstimo do termo salão dos eventos homônimos realizados no campo das artes plásticas indicava seu caráter seletivo e competitivo, com atribuição de premiações aos melhores trabalhos a partir da avaliação de um júri. Nesse caso, além do desenho e da pintura, foram incluídas outras categorias, como a música e a poesia (ARTE..., 10 abr. 1961, p. 7).

Presentes na cena brasileira desde a década de $1930^{2}$, o salões de arte

1 A Galeria de Arte da Folha (ou das Folhas), localizada na cidade de São Paulo, foi criada por Isaí Leirner, um dos diretores do Museu de Arte de São Paulo, tendo contado com o apoio do Grupo Folha, responsável pela edição da Folha de São Paulo. A iniciativa inseriu-se num movimento maior de ampliação do mercado de arte no Brasil, que incluiu a abertura de galerias comerciais de arte nas principais cidades brasileiras. (GALERIA..., 2018). Segundo Vieira, o espaço tinha por finalidade não apenas "honrar-se com exposições de pioneiros", mas também "descobrir e apresentar valores novos como futuro que quer ser das diversas gerações de artistas" (VIEIRA, 30 mai. 1961, p. 4).

2 Podermos citar como exemplos de eventos dessa ordem anteriormente vistos o I Salão de Arte Infantil (1937), ocorrido em Campinas e promovido pelo Centro de Ciências, Letras e Artes (SALÃO..., 11 nov. 1937, p. 17), o $1^{\circ}$ Salão de Arte Infantil, organizado na cidade de São Paulo como parte da Segunda Semana de Arte Moderna (1 ${ }^{\circ}$ SALÃO..., 10 ago. 1941, p. 1), o Salão da Criança Carioca (1942), envolvendo instituições educacionais (SALÃO..., 27 jan. 1942, p. 6), ou o Salão de Arte Infanto-juvenil (1952-1960), organizado anualmente pela Secretaria pela Secretaria 
infantil somavam-se a outras mostras de crianças que tinham por objetivo colocar em evidência a importância da arte nos processos educativos a partir do princípio da liberdade de expressão. Tais pressupostos se baseavam em tendências na educação, na psicologia e na arte que vinham de meados do século XIX e que tiveram defensores históricos como Rousseau, Spencer, Sully, Cizek, Dewey, Richardson, Read e Lowenfeld, entre tantos outros, que ora buscavam nos desenhos e pinturas infantis chaves para a compreensão da personalidade e do desenvolvimento humano, ora atribuíam-lhes valores estéticos dignos de apreciação. Essas ideias contribuíram para o delineamento do termo arte infantil, utilizado pelo evento promovido pela Folha de São Paulo e que, segundo Viola (1936, p. 9), pressupunha a concepção da arte como criação, para além das ideias de exatidão, talento ou cópia da natureza, e o respeito à personalidade da criança, independentemente da sua condição de futuro adulto. Ao longo da primeira metade do século XX, cresceu a convicção de que, assim como a educação de um modo geral, a educação artística de crianças deveria seguir sua natureza de forma não diretiva.

A partir de eventos como a mostra de desenhos e pinturas de crianças inglesas organizada por Herbert Read em $1941^{3}$ e, posteriormente à Segunda Guerra Mundial, de outras ações análogas coordenadas pela $\mathrm{UNESCO}^{4}$, as exposições de arte infantil, que circulavam por diferentes países e regiões, passaram a ser consideradas ferramentas eficazes para a promoção da paz e do bom entendimento entre os povos, contribuindo para a formação de adultos mais tolerantes e compreensivos em relação às mútuas diferenças ${ }^{5}$. Sua popularização mobilizou artistas e intelectuais, fomentando debates sobre a importância da arte nos processos educacionais ${ }^{6}$. Porém, ao lado das justificativas e aspectos educacionais ou humanitários, logo ficou evidente seu considerável potencial midiático, o que despertou o interesse de instituições e órgãos de imprensa com objetivos de propaganda institucional. Este foi o caso do I Salão de Arte Infantil, extensamente explorado pela Folha de São Paulo em suas diversas

de Educação e Cultura do governo de Pernambuco com o apoio do Diário de Pernambuco, jornal que fazia parte do conglomerado Diários Associados. (SALÃO..., 23 nov. 1952, p. 9).

3 Sobre exposições de arte infantil, ver: Osinski, Antonio (2010a e 2010b); Osinski (2014).

4 A partir de sua criação, em 1945, a UNESCO promoveu diversas ações de incentivo à arte infantil, entre elas seminários para a discussão dos problemas relacionados à educação artística e a publicação de obras sobre o assunto, como o livro Art et Éducation,

5 Sobre esse assunto, ver: Osinski (2001; 2008); Antonio (2012); Osinski (2008).

6 No Brasil, a exposição das crianças inglesas organizada por Read itinerou por diversas cidades, incluindo o Rio de Janeiro, São Paulo, Belo Horizonte e Curitiba, dando origem a um movimento que resultou nas escolinhas de arte, instituições de frequência livre desvinculadas dos sistemas oficiais de ensino, e das quais a Escolinha de Arte do Brasil, fundada em 1948 pelo artista plástico Augusto Rodrigues, é exemplo pioneiro. (INEP, 1980). 
fases de organização com a publicação de matérias quase diárias, por meio das quais pudemos apreender um pouco sobre seu funcionamento.

Demandando um processo de seleção intrincado que envolveu diversos órgãos governamentais, a escolha dos trabalhos se iniciava nas próprias escolas, ficando essa fase sob a responsabilidade dos diretores e auxiliares de inspeção de cada instituição escolar. Uma segunda fase seletiva acontecia nas delegacias regionais de ensino, para então ser realizada uma última seleção, já nas dependências da Folha, em São Paulo. (BOTUCATU..., 1 jun. 1961, p. 2). A cifra de um milhão e trezentas mil participantes, desde o processo inicial de seleção nas diversas modalidades, foi por várias vezes mencionada nas matérias veiculadas. (ABRE-SE..., 21 jun. 1961, p. 1).

No caso das artes plásticas, foram remetidos à capital paulista, para a fase final, 969 trabalhos de alunos oriundos de diferentes escolas e cidades, sendo 807 desenhos e 192 pinturas. O júri, composto por especialistas das artes plásticas ${ }^{7}$, escolheu 50 trabalhos de crianças de 32 cidades paulistas para participar da exposição (JURI..., 16 jun. 1961, p. 14).

A abertura oficial do I Salão de Arte Infantil se deu com a inauguração da exposição, à qual compareceram numerosos convidados e autoridades. (ABRE-SE..., 22 jun. 1961, p. 1). No mesmo dia, a comissão julgadora enalteceu publicamente o concurso, considerado por eles "um elemento de estímulo à expressão artística da criança e de incentivo aos pais e mestres" e "um alerta à necessidade de desenvolvimento de uma consciência mais profunda da utilidade do ensino artístico em bases pedagógicas mais adiantadas". (ABRE-SE..., 21 jun. 1961, p. 1). Nos dias seguintes, o auditório da Folha de São Paulo se tornou palco das apresentações finais de música e declamações de poesias para a escolha dos laureados, contando com grande audiência que incluiu alunos das escolas que participavam do certame.

O Salão despertou o interesse de intelectuais como o crítico de arte José Geraldo Vieira que, a partir de seu envolvimento como jurado do certame e como membro do conselho da Galeria da Folha, tornou públicas algumas reflexões sobre a expressão artística infantil na coluna diária intitulada Artes Plásticas, mantida por ele naquele jornal.

7 Presidido pelo colecionador de arte e membro do Conselho da Galeria da Folha, Isaí Leirner, o júri incluía ainda os críticos de arte José Geraldo Vieira (também membro desse Conselho), Maria Eugênia Franco, Marc Bercowitz, Nelson Coelho e Quirino Campofiorito, além do museólogo e professor de história da arte Wolfgang Pfeiffer e dos artistas Fernando Lemos, Italo Cencini e Willy de Castro. (ABRE-SE..., 21 jun. 1961, p. 1). 


\section{Um crítico de arte e algumas notas sobre o fazer artístico infantil}

Naquele momento, a posição de José Geraldo Vieira (Rio de Janeiro, 1897 - São Paulo, 1977) na crítica de arte se equiparava às de outros intelectuais reconhecidos do período, como Sérgio Milliet, Quirino Campofiorito ou Mário Pedrosa, tendo suas relações com as artes plásticas sido construídas gradativamente ao longo de sua trajetória. De origem familiar açoriana, Vieira teve uma formação sólida que incluiu, além de estudos superiores, também viagens ao exterior ${ }^{8}$. Escritor associado às correntes modernistas ${ }^{9}$ e dedicado não só à literatura, mas também à tradução ${ }^{10} \mathrm{e}$ à crítica literária, ele pode ser considerado um intelectual na acepção de Gramsci (2004, p. 53), pois participou ativamente da organização da cultura de seu tempo, manifestando-se publicamente sobre assuntos ligados à literatura e às artes plásticas na imprensa e em conferências sobre temas variados ${ }^{11}$. Eleito membro da Academia Paulista de Letras em 1948, aos 51 anos, exerceu a atividade docente na Faculdade de Comunicação Social Casper Líbero (GARCIA, 2003), tendo feito parte de associações de classe ${ }^{12} \mathrm{e}$ integrado inúmeras comissões julgadoras de concursos de literatura ${ }^{13}$

8 José Geraldo Manuel Germano Vieira Drummond Machado da Costa Fortuna estudou no Colégio Santa Rosa, de Niterói, dirigido pelos padres salesianos, onde se formou em Ciências e Letras (1911), e mais tarde concluiu a Faculdade de Medicina do Rio de Janeiro (1919). Sua formação literária e artística, já em construção desde a adolescência, foi adensada por ocasião de viagem à Europa para aperfeiçoamento na área de Radiologia, quando teve a oportunidade de entrar em contato com a produção cultural europeia do período. Em 1946 abandonou definitivamente a carreira de médico para se dedicar às letras. (GARCIA, 2003).

9 São bastante mencionadas pela crítica as seguintes obras de sua autoria: A mulher que fugiu de Sodoma (1931), A Quadragésima Porta (1943), A Ladeira da Memória (1950), O Albatroz (1952), Terreno Baldio (1961) e A Mais que Branca (1974), entre outras obras que José Geraldo Vieira produziu. (GARCIA, 2003).

10 Entre os diversos autores traduzidos por Vieira, estão Dostoiewski, Hemingway, Pirandello, Mark Twain, Joyce, Steinbeck, Stendhal e Tolstoi. (ESCORSIM, 2016).

11 Sua preocupação com a mediação direta do conhecimento com o público foi notada pela articulista do Correio da Manhã, Lúcia Pereira (28 set. 1952, p. 2) que o citou, ao lado de Sérgio Milliet e Domingos Carvalho da Silva, como exemplos de intelectuais que "estão sempre falando, e sendo ouvidos".

12 Vieira foi presidente da Associação Brasileira de escritores (ASSOCIAÇÃO..., 27 jan. 1950, p. 3), diretor e membro fundador da Federação das Associações Culturais de São Paulo (J.C., 10 mai. 1955, p. 14) e membro da Associação Brasileira dos Críticos de Arte, além de integrar comissões organizadoras de eventos que reuniam a classe intelectual, como a Convenção Municipal de Intelectuais e Artistas de São Paulo. (CONDÉ, 3 fev. 1956, p. 12).

13 Como exemplos citamos o Prêmio Fábio Prado de Literatura, em 1949, o Prêmio de Poesia Mário de Andrade, em 1955 (J. C., 10 mai. 1955, p. 14) e o Prêmio Carmem Dolores de melhor livro do ano, conferido em 1957 a Guimarães Rosa pela obra Grande sertão - Veredas. (PREMIADO..., 16 mar. 1957, p. 6). 
A atuação como crítico de arte se iniciou em 1954, com a colaboração na revista Habitat, a qual se estenderia até 1965, concomitantemente à atuação análoga na Folha da Manhã e, mais tarde, em 1961, na Folha de São Paulo ${ }^{14}$. Essa atividade resultou em convites para participação em comissões de salões de $\operatorname{arte}^{15}$, com destaque às Bienais de São Paulo, eventos de importância máxima na cena artística brasileira ${ }^{16}$.

Desvinculadas de modelos teóricos e de caráter conciliatório (SILVA, 2012, p. 18-19), as crítica de arte de Vieira são próprias de alguém aberto às tendências variadas, aspecto que foi notado pelo contemporâneo Jayme Maurício:

José Geraldo Vieira vai a todas as mostras e comenta tudo o que se expõe com um entusiasmo, uma superior visão da efervescência artística que vai pelo país, sem dogmatismos, sem ortodoxia, sem aquele abominável tom de alguns confrades que parecem desejar orientar e não interpretar ou analisar a criação artística. (MAURÍCIO, 19 jul. 1961, p. 2).

Para o intelectual, a crítica era inseparável dos misteres do jornalismo (VIEIRA, 6 abr. 1961, p. 5) exigindo do profissional desta área, além de sintonia com os acontecimentos cotidianos, também familiaridade com os materiais e técnicas utilizados pelo artista e conhecimentos nos campos humanístico, histórico e estético, "sem falar no dom analítico de exegese crítica e no dom sintético de concluir e julgar”. (VIEIRA, 21 mar. 1961, p. 3).

Uma breve análise dos textos publicados em sua coluna naquele ano de 1961 nos dá uma ideia do universo em que se movia e das escolhas temáticas que fazia. Foram mais de 300 artigos publicados, sempre no Caderno Ilustrada, sendo a maioria sobre artistas que expunham no momento. Eventos como a Bienal de

14 Vieira também colaborou com o quinzenário Paratodos no período entre 1956 e 1958, periódico editado no Rio de Janeiro por Jorge Amado. (SILVA, 2012).

15 Podemos citar como exemplos o Prêmio de Arte Contemporânea, do qual participou em 1956 e 1959 (MAURÍCIO, 20 dez. 1956, p. 16), o Salão Nacional de Arte Moderna, cujo júri integrou em 1957 (MAURÍCIO, 01 mai. 1957, p. 16) ou o II Salão Anual de Curitiba, realizado naquele ano na capital paranaense. (VIEIRA, 11 abr. 1961, p. 3).

16 José Geraldo Vieira fez parte dos Júris de Seleção ou Premiação daquele evento em seis edições, em 1955, 1957, 1961, 1963, 1965 e 1967, duas das quais por indicação dos artistas concorrentes (1957 e 1961), numa demonstração de prestígio junto a eles. Integrou também o Júri de Premiação em duas oportunidades, em 1963 e 1971. (SILVA, 2012). 
São Paulo e outros salões de arte foram objetos de matérias que privilegiavam o que ocorria naquela cidade, embora notas sobre o que se passava no Rio de Janeiro e em outros centros do país e do mundo também aparecessem com menos frequência ${ }^{17}$. Bastante exploradas nos textos de Vieira foram as mostras ocorridas na Galeria da Folha, possivelmente em decorrência de questões contratuais.

Inserida naquele contexto, a exposição de desenho e pintura do I Salão de Arte Infantil motivou a elaboração de seis artigos de sua autoria ${ }^{18}$, publicados nos meses de junho e julho, mais ou menos em sequência e de forma encadeada. Ao contrário das outras matérias que saíram no mesmo veículo sobre o assunto, de caráter mais informativo sobre os preparativos e a realização do projeto, Vieira aproveitou aquele espaço para tecer considerações de ordem mais geral e de caráter mais reflexivo sobre a produção artística infantil, abordando questões sobre o desenho e a pintura, os assuntos explorados pelas crianças, as relações entre imaginação e realidade na arte infantil e as aproximações entre a arte infantil e a arte dita "primitiva".

O primeiro artigo foi publicado em 21 de junho, dia da abertura da exposição dos trabalhos das crianças. Como uma forma de responder ao possível estranhamento dos leitores habituais ao se depararem com um assunto que escapava da esfera mais consolidada das artes plásticas, Vieira (21 jun. 1961, p. 3) mencionou a constante cobertura jornalística do evento que vinha já de alguns meses e afirmou ser "natural, portanto, que este setor de artes visuais se manifeste sobre o desenho a pintura das crianças de até os doze anos de idade". Algumas das ideias expressas nesses artigos dialogam com documento publicado naquele mesmo dia e assinado pela comissão julgadora do Salão, da qual Vieira fez parte, que buscou esclarecer os critérios adotados e também dar sugestões para as próximas edições.

Fazendo referência aos princípios da livre-expressão na arte e da não interferência de adultos, defendidos por teóricos como Herbert Read (2001), os jurados declararam ter agido "não no sentido de escolher e premiar obras de arte, mas sim de analisar aquilo que, por seu mau gosto estético, teria sido talvez mais da responsabilidade adulta do que propriamente infantil". Recomendaram ainda aos pais ou professores para que orientassem seus alunos ou filhos quanto

17 Foram encontradas referências a instituições situadas em países da Europa, nos Estados Unidos e na Argentina. Também eventualmente exposições ou salões que ocorriam em outras cidades, como Salvador, Belo Horizonte ou Curitiba eram exploradas por suas críticas.

18 Os artigos foram os seguintes: I Salão de Arte Infantil (VIEIRA, 21 jun. 1961, p. 3); O desenho no I Salão Infantil (VIEIRA, 29 jun. 1961, p. 3), A pintura no I Salão Infantil (VIEIRA, 30 jun. 1961, p. 3), Os temas e a arte infantil (VIEIRA, 4 jul. 1961, p. 3), A imaginação e a realidade na arte infantil (VIEIRA, 5 jul. 1961, p. 2) e Aproximações entre a arte infantil e a primitiva (VIEIRA, 6 jul. 1961, p. 3). 
ao uso do material, mas sem interferir em sua escolha ou durante o processo criativo, "em relação ao qual a criança deve sentir-se absolutamente livre". (ABRE-SE..., 21 jun. 1961, p. 1).

Tendo igualmente como ponto central a defesa da liberdade expressiva, os textos de Vieira giraram em torno da ideia central de que haveria duas fases na expressão da criança pela arte: a "espontânea", inerente às crianças até dez anos, e a "dirigida", típica de crianças maiores. (VIEIRA, 21 jun. 1961, p. 3). O período inicial é relacionado pelo autor com a imaginação, sendo por ele mais valorizado por advir de seu mundo interior:

$\mathrm{Na}$ fase inicial, é o seu mundo que ela desenha ou pinta. E não propriamente o mundo mesmo dos adultos. Bichos e flores, como colegas da Criação; barquinhos, como veículos de fuga; circos, como espetáculos. E cores, o azul, o vermelho, o verde, como o céu, o sol, a relva, o lago. (VIEIRA, 21 jun. 1961, p. 3).

Essa foi também opinião da comissão julgadora, que atribuiu os primeiros prêmios às crianças mais novas e justificou essa decisão pela

[...] preocupação do júri em prestigiar mais os princípios que regem a expressão infantil - e que são mais positivos nas idades menores - e considerar secundários os fins a que chegam algumas crianças, as mais adiantadas e bem orientadas, nas idades maiores, quando se sabe que então termina a chamada idade infantil e que, na experiência plástica a criança principia a imitar a realidade, fugindo à expressão espontânea. (ABRE-SE..., 21 jun. 1961, p. 1).

Para Vieira, imaginação e realidade são ambas matrizes sólidas, a primeira renovando e a segunda oferecendo os temas da arte. Porém, enquanto os temas oriundos da imaginação se justificariam por sua "riqueza absurda, poética e inédita", a realidade valeria apenas por sua "pobreza prosaica que está a implorar ao artista que a sublime e que a salve de seu aspecto fotográfico". O interesse da criança apenas pelo real poderia ser considerado um mau presságio de que, não tendo mais a imaginação a dar suporte à sua arte, ela se tornaria "um pre- 
coce adulto escravizado à rotina do cotidiano". (VIEIRA, 5 jul. 1961, p. 2). A imaginação deveria, então, cumprir a função de enriquecer a realidade:

Quando os desenhos e as pinturas tendem nas crianças a uma exatidão formal, sem desfigurações, há apenas habilidade passageira ou permanente para a captação de coisas e fatos. Seus autores serão futuros medíocres. Mas se nos desenhos e pinturas de crianças já quase adolescentes perdurar a imaginação e a síntese da infância propriamente dita, seus trabalhos terão sempre uma candura de ingenuidade técnica mesmo se o tema for experto e vivaz. (VIEIRA, 5 jul. 1961, p. 2).

O estudioso francês do desenho infantil Rouma (1913, p. 171) definiu a imaginação criadora expressa nos desenhos espontâneos infantis como "um processo de atividade intelectual por meio do qual os elementos tomados da memória são modificados em proporções variadas, simplificados, alterados, associados ou dissociados, combinados em novas sínteses ${ }^{19}$ ". Essa relação com o mundo real foi também enfatizada por Luquet (1927) e mais tarde referendada por Piaget (KELLY, 2004, p. 102-103) e Lowenfeld (1961). Tais autores desenvolveram classificações da produção das crianças em estágios progressivos de acordo com o seu crescimento, qualificando os iniciais como mais introspectivos e esquemáticos, e os mais avançados como mais vinculados aos elementos visuais circundantes.

Segundo Vieira (29 jun. 1961, p. 3), na "criança propriamente dita", o desenho seria interessante "como registro pessoal exteriorizando um mundo de fantasia, espécie de istmo que liga a imaginação ao real", o qual descarregaria "a carga superior, sincera e autônoma da sensibilidade infantil no território ainda vago e disponível da percepção geral da vida". Atuando como um diário inconsciente, seu grafismo seria a exteriorização, por meio de "esquemas interiores, anímicos, de elã vital puro", de "ideias contidas em devaneios e solilóquios":

19 Tradução da autora. Do original: "Par imagination créatrice j'entends ici ce processus de l'activité intellectuelle par lequel des élements empruntés à la mémoire sont modifiés dans des proportions variées, sont simplifiés, intensifiés, altérés, sont associés ou dissociés, sont combinés dans des synthèses nouvelles. (ROUMA, 1913, p. 171). 
Seus traços são linhas esquemáticas e nunca volumes. E as cores são sempre, como repleção ou mesmo ainda como linhas, as cores fundamentais: o azul, o encarnado e o verde. Quanto à temática, ainda não é a doméstica, de casa, nem a da natureza. Trata-se ainda dum mundo amorfo, suposto, surrealista e onírico. Na verdade, signos e metonímias. Verdadeiros ideogramas. (VIEIRA, 29 jun. 1961, p. 3).

Nessa fase, não seria aconselhável haver interferência dos pais e professores, os quais deveriam deixar a criança plenamente livre para continuar a ser "um Miró, um Klee, dona absoluta do onirismo e do surrealismo" (VIEIRA, 21 jun. 1961, p. 3), podendo a semelhança de seus trabalhos com a produção de tais artistas valer como verdadeiros "testes de qualificação vocacional". (VIEIRA, 6 jul. 1961, p. 2). Isso ficou claro também nos conselhos dados aos orientadores dos futuros concursos pela comissão julgadora, para que evitassem "a colocação nas margens do papel das cercaduras que procuram imitar, mais do que a moldura, a convenção e o preconceito de obra de arte que isso implica", representando uma "limitação perigosa para o ato de criação infantil". (ABRE-SE..., 21 jun. 1961, p. 1). A transgressão de um dos participantes em favor da liberdade expressiva foi mesmo mencionada por eles de forma elogiosa:

[...] A propósito, verificou-se num dos desenhos premiados o gesto espontâneo da criança, não hesitando em ultrapassar o traço vermelho, provavelmente imposto pela educadora, antes mesmo de ter sido executado o desenho. (ABRE-SE..., 21 jun. 1961, p. 1).

O trabalho artístico das crianças menores, na opinião de Vieira mais interessante por ser "artístico por instinto" e ter "um poder infuso", seria caracterizado pelo uso do lápis e do papel, materiais considerados por ele adequados àquela faixa etária, e da exploração de "motivações absurdas, fantásticas, de pura imaginação". (VIEIRA, 30 jun. 1961, p. 3). Tais temas expressariam inicialmente o interior da criança, assimilando gradualmente aspectos do mundo exterior por meio de elementos formais, cujas características seriam de síntese e ausência de detalhes. Funcionariam, assim, como "séries limitadas de ideogramas, espécie de alfabeto semântico mais do que sílabas léxicas" (VIEIRA, 4 jul. 1961, p. 3), sendo inteligíveis apenas para a criança que os realizou: "Isso, que por falta de 
analogia gráfica parece absurdo aos olhos e aos ouvidos do adulto, para a criança é a sua verdade, o esquema da sua percepção subjetiva, mais do que objetiva". (VIEIRA, 4 jul. 1961, p. 3).

Já a fase seguinte, da pré-adolescência, a partir dos 11 anos de idade, é vista com menos entusiasmo, pois seria o momento em que a criança passa a registrar aspectos do mundo real, perdendo então muito de sua pureza expressiva:

Já a criança em contato com a realidade, o passeio, a rua, a paisagem, os bichos, os adultos, isto é, a criança dos últimos anos primários de escola, principia a perder a fantasia, a liberdade, a inocência, e passa então a desenhar diante de modelos amplos como o mar, a montanha, o circo, a floresta, o jardim zoológico, as pessoas. (VIEIRA, 29 jun. 1961, p. 3).

A realização de composições com mais objetividade pelas crianças maiores é considerada uma "contaminação da imaginação disponível da criança pelo mundo exterior" (VIEIRA, 4 jul. 1961, p. 3). Não obstante, esse período poderia ser positivo caso elas exteriorizassem o mundo real "através de uma preservação feliz de sua memória" ao invés de se fixarem na tentativa de uma representação mais realista, vista como prejudicial à imaginação:

Ora, é exatamente a imaginação manifestada em sua pureza absurdamente misteriosa que faz discernir na criança que desenha ou pinta uma vocação para arte. Se logo se tomar duma exatidão estilística em face do que vê, propenderá para a mediocridade". (VIEIRA, 5 jul. 1961, p. 2).

Não obstante, somente na fase da pré-adolescência seria possível perceber a existência de uma eventual vocação, cujos sinais seriam, primeiramente, a persistência do hábito de desenhar e, mais tarde, o despertar pelo interesse na pintura. Segundo Vieira, o abandono dos esquemas lineares em favor da pintura de manchas e formas poderia indicar uma provável vocação artística, a qual poderia ser confirmada pela existência de características como "ritmo, contraste, história, episódio, fixação especial e sensível do mundo interior e do mundo exterior". (30 jun. 1961, p. 3). As liberdades de invenção nos temas e de expressão no tratamento 
plástico das cores, massas e volumes seriam, assim, as características comuns na pintura infantil de época escolar primária. Só a partir daí ela deveria ser orientada artisticamente, "mas aos poucos, sem impacto, como gradual despertar da inocência para o pesadelo de viver mesmo". (VIEIRA, 21 jun. 1961, p. 3). Nesse processo, o tema não deveria ser o critério mais importante na avaliação do orientador, o qual deveria prestar atenção a outros aspectos, como a destreza, o uso das cores, contrastes, etc. Vieira demonstra preocupação com a preparação de futuros artistas, o que fica expresso em afirmações como a de que "há que se selecionar as (vocações) acima da mediocridade coletiva". (VIEIRA, 30 jun. 1961, p. 3 ).

A ideia da imaginação como um valor positivo e distante das representações mais realistas, expressa por Vieira, pode ser relacionada com as discussões referentes à arte moderna, que procurou desvincular a produção artística das rígidas regras acadêmicas então praticadas, que privilegiavam representações de ordem mais realista, baseadas na observação, no conhecimento da anatomia e em proporcionalidades e leis perspectivas. Artistas vinculados a movimentos artísticos do final do século XIX e início do século XX, como o impressionismo, o pós-impressionismo, o expressionismo e o cubismo, entre outros, procuraram se afastar "do mundo exterior e voltaram-se para o mundo interior dos sentimentos, em busca de seus temas" (CHIPP, 1996, p. 45), no intuito de alcançar formas de expressão e soluções formais menos convencionais. O pintor Maurice Denis (Apud CHIPP, 1996, p. 102) definiria em 1909 a imaginação como a "rainha das nossas faculdades", sendo a arte concebida como "a deformação subjetiva da natureza". Já o norueguês Edvard Munch (apud CHIPP, 1996, p. 111) afirmaria, no mesmo período, ser a arte oposta à natureza: "Uma obra de arte só pode provir do interior do homem", opinião compartilhada por Emil Nolde (apud CHIPP, 1996, p. 143), para quem "A imitação fiel e exata da natureza não cria uma obra de arte [...], nada provoca além de repugnância".

Nesse contexto, os ensinamentos obtidos nas academias de arte passaram a ser vistos de forma pejorativa e o autodidatismo avaliado positivamente, $o$ que se percebe nas reflexões de Kandinsky (apud CHIPP, 1996, p. 167) de que: "quando um indivíduo que não recebeu nenhuma formação artística, e que, portanto, está livre dos conhecimentos artísticos objetivos, pinta alguma coisa, o resultado nunca é uma obra vazia". A ideia de começar do zero se tornou recorrente e foi frequentemente publicizada em textos como o de Vlaminck (apud CHIPP, 1996, p. 140), que afirmou, em relação aos museus, fugir "de seu odor, de sua monotonia e sua severidade", ou o Manifesto futurista, escrito por Marinetti (apud CHIPP, 1996, p. 290) que manifestou o desejo de "destruir os museus, as bibliotecas, as academias de todo tipo". Esses posicionamentos abriram caminho para a apreciação, por parte de críticos de arte e artistas modernos, da arte antiga ou dos povos ditos "primitivos", então em plena descoberta em 
decorrência de pesquisas impetradas pela arqueologia e pela antropologia, ou do que passou a ser chamado de "arte ingênua", realizada por autodidatas sem conhecimentos prévios perspectivos ou formais. Tais manifestações passaram a não ser mais consideradas cruas, mas formas de arte expressivas e sensíveis. (MACDONALD, 2004, p. 329).

A analogia da produção artística das crianças pequenas com a arte primitiva, especialmente pelo uso recorrente de certos esquemas, também foi fator decisivo para a aceitação da primeira no campo da arte. A comparação do desenvolvimento do indivíduo com a da humanidade, por teorias surgidas ao final do século XIX, levou à ideia de que ambos seriam estágios iniciais da vida - individual ou social - e por isso mais puros, assim como sua arte. Artistas moderno ${ }^{20}$ como Paul Klee e Joan Miró, citados por Vieira, tiveram com frequência seus trabalhos associados à arte infantil por críticos e historiadores. Isso se deve ao fascínio pelas soluções formais originais e criativas alcançadas pelas crianças, o que os levou a incorporá-las em sua produção. Miró buscou inspiração na espontaneidade e no diálogo mais estreito com o inconsciente, presentes no processo de criação dos pequenos (VALLIER, 1998, p. 204-205). No caso de Klee, essa opção foi assumida em declarações como a de que os trabalhos de seu filho Felix seriam melhores que os seus, por não serem filtrados pelo cérebro (WILSON, 1990, p. 57), ou de que os trabalhos artísticos dos "primitivos", dos doentes mentais e das crianças eram exemplos a serem seguidos por suas relações com os primórdios da arte. Para ele, a falta de diálogo com o conhecimento em arte tornava as produções infantis mais dignas de interesse, sendo a influência sofrida por obras de arte considerada uma forma de corrupção. (FRANCISCONO, 1998, p. 105).

A comparação dos trabalhos das crianças com a produção de artistas considerados "ingênuos" ou "primitivos" também foi objeto de reflexão de Vieira, para quem a ingenuidade, a candura e a sínteses seriam características em comum entre as duas manifestações. Além de Klee e Miró, artistas como o francês Henri Rousseau, o mexicano José Guadalupe Posada e o brasileiro José Antonio da Silva foram citados pelo autor como exemplos da "permanência de um módulo infantil" e da "persistência da síntese gráfica pueril mesmo em temas de imaginação quase onírica diante da realidade mais objetiva" (VIEIRA, 06 jul. 1961, p. 3). Para ele, tais artistas seriam adultos maduros que trabalhavam como se fossem crianças geniais, "não por interpretarem certo o mundo, mas por sempre o terem visto com a candura sagaz das crianças". (VIEIRA, 6 jul. 1961, p. 3).

20 Outros artistas modernos se voltaram para a arte infantil como uma fonte de inspiração, a exemplo de Kandinsky, Larionov, Roger Fry ou os futuristas russos. Sobre esse assunto, ver Finenberg (1998). 
Contudo, as contradições inerentes de um concurso que pregava a liberdade de expressão, mas cujo processo de seleção era altamente excludente, não passaram despercebidas para Vieira e seus colegas membros do júri. Preocupados com a consciência, da parte das crianças, de estar participando de um evento competitivo, e seus supostos efeitos negativos, sugeriram que para as próximas edições elas não fossem informadas de estar desenhando ou pintando para uma competição, "pois com isso se evitariam prejuízos psicológicos, morais e pedagógicos". Da mesma forma, as crianças premiadas deveriam ser orientadas "psicologicamente a não supervalorizar seu prêmio, nem em relação a si mesma, nem em sua convivência com os condiscípulos". (ABRE-SE..., 21 jun. 1961, p. 1). Tal posição, entretanto, não impediu sua participação nesse tipo de certame, já condenado em 1954 por especialistas como o americano Lowenfeld (1977, p. 68-69). Para esse educador, os concursos de arte envolvendo crianças eram prejudiciais aos processos educacionais em arte por constituírem estímulos artificiais que, ao premiarem uns, desestimulam outros, exercendo má influência na personalidade dos participantes por suprimir as diferenças individuais, interferindo em sua criatividade natural.

\section{Considerações finais}

Os artigos publicados por José Geraldo Vieira envolvendo a temática da expressão artística da criança constituem exceção em sua produção como crítico de arte, centrada no universo da arte como profissão e em seus artistas. Entretanto, podem ser considerados parte de um movimento mais amplo que envolveu intelectuais e artistas em torno da prática e da temática da arte infantil, guardando relações estreitas não só com as tendências de educação em arte e da própria arte moderna, que vinham de meados do século XIX e que defendiam a liberdade de expressão infantil, mas também com o discurso professado pelos organizadores do I Salão de Arte Infantil, com cuja organização estava diretamente envolvido em várias instâncias.

Para Vieira, as produções das crianças menores eram consideradas mais ricas em valores estéticos por sua riqueza imaginativa e uma maior relação com o próprio mundo interior do que com a realidade circundante, vista como negativa para expressão infantil. Entretanto, era nas crianças maiores que se deveria, segundo ele, procurar as "vocações" que resultariam em futuros artistas, preocupação bastante evidente de sua parte, que pode ser relacionada com sua atividade no campo artístico profissional. Mesmo assim, só teriam futuro aquelas 
que conservassem as características consideradas puras das fases anteriores, sendo qualquer esforço em direção de uma representação realista relacionado com a mediocridade.

Defendendo o princípio de que toda a criança é capaz de se expressar através da arte, tais mostras carregavam em seu cerne contradições que diziam respeito especialmente aos processos de seleção e eventual premiação, feitos por adultos especialistas a partir de critérios por eles estabelecidos, que privilegiavam a suposta "espontaneidade" ou "criatividade" de alguns trabalhos em detrimento dos outros. Entretanto, mesmo conscientes de tais contradições, Vieira e seus companheiros artistas e críticos limitaram-se a propor medidas paliativas para os próximos eventos, omitindo-se a criticar sua essência.

\section{REFERÊNCIAS}

$1^{\circ}$ SALÃO de Arte Infantil. A Manhã, Rio de Janeiro, 10 ago. 1941, p. 1.

ABRE-SE o I Salão de Arte Infantil. Folha de São Paulo, São Paulo, 22 jun. 1941. Assuntos Diversos, p. 1.

ABRE-SE hoje na Galeria de Arte da "Folha" o I Salão de Arte Infantil. Folha de São Paulo, São Paulo, 21 jun. 1961. Folha Ilustrada, p. 1.

ASSOCIAÇÃO Brasileira de Escritores. Jornal de Notícias, São Paulo, 27 jan. 1950, p. 3. ANTONIO, R. C. Um oásis de sombra e luz em cada escola: As escolinhas de arte e a formação do homem do futuro (1960-1970). Curitiba: Editora UFPR, 2012.

ARTE infantil na Folha. Folha de São Paulo, São Paulo, 20 abr. 1961. $1^{\circ}$ caderno, p. 7. BOTUCATU seleciona trabalhos para o Salão de Arte Infantil. Folha de São Paulo, São Paulo, 1 jun. 1961. $2^{\circ}$ Caderno, p. 2.

CHIPP, H. B. Teorias da arte moderna. Tradução: Waltensir Dutra ...et al. São Paulo: Martins Fontes, 1996.

CONDÉ, J. Escritores e livros. Correio da Manhã, Rio de Janeiro, 03 fev. 1956. $1^{\circ}$ Caderno, p. 12.

ESCORSIM, F. Conhecendo José Geraldo Vieira. In: VIEIRA, J. G. Impressões \& Expressões. Organização e seleção de Daniel André Pacheco Fernandes. Curitiba: Arcádia, 2016.

FINENBERG, J. Discovering Child Art: essays on childhood, primitivism and modernism. Princeton: University Press, 1998. 
FRANCISCONO, M. Paul Klee and children's art. In: FINENBERG, J. Discovering Child Art: essays on childhood, primitivism and modernism. Princeton: University Press, 1998.

GALERIA de Artes das Folhas (São Paulo, SP). In: ENCICLOPÉDIA Itaú Cultural de Arte e Cultura Brasileiras. São Paulo: Itaú Cultural, 2018. Disponível em: <http://enciclopedia.itaucultural.org.br/instituicao290117/galeria-de-artes-das-folhas-sao-paulo-sp>. Acesso em: 31 mar. 2018.

GARCIA, M. A. José Geraldo Vieira (1897-1977): Fortuna crítica. 247 f. Dissertação (Mestrado em Letras). Faculdade de Ciências e Letras de Assis, UNESP, Assis, 2003.

GRAMSCI, A. Cadernos do Cárcere, volume 2. Tradução de Carlos Nelson Coutinho. Rio de Janeiro: Civilização Brasileira, 2004.

INEP (Instituto Nacional de Estudos e Pesquisas Educacionais). Escolinha de Arte do Brasil. Brasília, 1980.

J. C. Conversa. Correio da Manhã, Rio de Janeiro, 10 mai. 1955. $1^{\circ}$ Caderno, Escritores e Livros, p. 14.

J. C. Periscópio. Correio da Manhã, Rio de Janeiro, 31 mai. 1955. $1^{\circ}$ Caderno. Escritores e Livros, p. 14.

JURI seleciona 50 pinturas no Salão de Arte Infantil. Folha de São Paulo, São Paulo, 16 jun. 1961. Folha Ilustrada, p. 14.

KELLY, D. D. Uncovering the History of Children's Drawing and Art. Westport, Connecticut, London: Praeger, 2004.

LOWENFELD, V. A criança e sua arte. São Paulo: Mestre Jou, 1977.

LOWENFELD, V. Desarollo de la capacidad creadora. Buenos Aires: Kapelusz, 1961.

LUQUET, G.-H. Le dessin enfantin. Paris : Lebrairie Felix Alcan, 1927.

MAURÍCIO, J. Alterado o Júri do Salão. Correio da Manhã, Rio de Janeiro, 01 mai. 1957. $1^{\circ}$ Caderno, Itinerário das Artes Plásticas, p. 16.

MAURÍCIO, J. Em São Paulo, no Museu de Arte Moderna. Prêmio de Arte Contemporânea. Correio da Manhã, Rio de Janeiro, 20 dez. 1956. $1^{\circ}$ Caderno, Itinerário das Artes Plásticas, p. 16.

MAURÍCIO, J. A "forma" do veterano crítico. Correio da Manhã, Rio de Janeiro, 19 jul. 1961. 2 Caderno, Itinerário das Artes Plásticas, p. 2.

MACDONALD, S. The History and philosophy of Art Education. Cambridge, Lutterworth Press, 2004.

OSINSKI, D. R. B. A modernidade no sótão: Educação e arte em Guido Viaro. Curitiba: Editora UFPR, 2008.

OSINSKI, D. R. B. Primeira Exposição de Desenho Infantil e Juvenil do Paraná: Uma 
renovação no conceito das exposições escolares (1943). Revista Brasileira de Educação (Impresso), v.19, p. 375 - 398, 2014.

OSINSKI, D. R. B. Arte, história e ensino: uma trajetória. São Paulo: Cortez, 2001.

OSINSKI, D. R. B.; ANTONIO, R. C. Exposições de arte infantil: bandeiras modernas pela construção do novo homem. Acta Scientiarum, Maringá, Education (Print), v. 32, p. 269-285, 2010a.

OSINSKI, D. R. B.; ANTONIO, R. C. Criança livre ou artista mirim? As exposições de arte infantil no Paraná (1940-1960). Impulso, Piracicaba, v. 20, p. 49-61, 2010b.

PEREIRA, L. M. Brecha perigosa. Correio da Manhã, Rio de Janeiro, 28 set. 1952. $2^{\circ}$ Caderno, p. 2.

PREMIADO Guimarães Rosa. Correio da Manhã, Rio de Janeiro, 16 mar. 1957. $1^{\circ}$ Caderno, p. 6.

READ, H. A educação pela arte. Tradução: Valter Lellis Siqueira. São Paulo: Martins Fontes, 2001.

ROUMA, G. Le langage graphique de l'enfant. Paris : Felix Albone \& Lisbonne, 1913.

SALÃO da Criança Carioca. O Jornal, Rio de Janeiro, 27 jan. 1942, p. 6.

SALÃO de Arte Infantil. Correio Paulistano, São Paulo, 11 nov. 1937, Notícias do Interior, Campinas, p. 17.

SALÃO de Arte Infanto-juvenil. Diário de Pernambuco, Recife, 23 nov. 1952. Artes e Artistas, p. 9.

SILVA, J. A. Pe. da. Introdução: José Geraldo Vieira, crítico de arte. In: VIEIRA, J. G.. Critica de Arte na Revista Habitat. São Paulo: Editora da Universidade de São Paulo, 2012. p. 11-35.

VALLIER, D. Miró and Children's Drawings. In: FINENBERG, J. Discovering Child Art: essays on childhood, primitivism and modernism. Princeton: University Press, 1998.

VIEIRA, J. G. I Salão de Arte Infantil. Folha de São Paulo, São Paulo, 21 jun. 1961. Caderno Ilustrada, Artes Plásticas, p. 3.

VIEIRA, J. G. A crítica de Arte. Folha de São Paulo, São Paulo, 21 mar. 1961. Caderno Ilustrada, Artes Plásticas, p. 3.

VIEIRA, J. G. A imaginação e a realidade na arte infantil. Folha de São Paulo, São Paulo, 05 jul. 1961. Caderno Ilustrada, Artes Plásticas, p. 2.

VIEIRA, J. G. A pintura no I Salão Infantil. Folha de São Paulo, São Paulo, 30 jun. 1961. Caderno Ilustrada, Artes Plásticas, p. 3.

VIEIRA, J. G. Aproximações entre a arte infantil e a primitiva. Folha de São Paulo, São Paulo, 06 jul. 1961. Caderno Ilustrada, Artes Plásticas p. 3. 
VIEIRA, J. G. Crítica e reportagem. Folha de São Paulo, São Paulo, 6 abr. 1961. Caderno Ilustrada, Artes Plásticas, p. 5.

VIEIRA, J. G. Encontro marcado na Galeria da Folha. Folha de São Paulo, São Paulo, 30 mai. 1961. Caderno Ilustrada, Artes Plásticas, p. 4.

VIEIRA, J. G. O II Salão Anual de Curitiba. Folha de São Paulo, São Paulo, 11 abr. 1961. Caderno Ilustrada, Artes Plásticas, p. 3.

VIEIRA, J. G. O desenho no I Salão Infantil. Folha de São Paulo, São Paulo, 29 jun. 1961. Caderno Ilustrada, Artes Plásticas. p. 3.

VIEIRA, J. G. Os temas e a arte infantil. Folha de São Paulo, São Paulo, 04 jul. 1961. Caderno Ilustrada, Artes Plásticas, p. 3.

VIOLA, W. Child Art and Franz Cizek. Viena: Austrian Junior Red Cross, 1936.

WILSON, B. Mudando conceitos da criação artística: 500 anos de arte-educação para crianças. In: Simpósio Internacional sobre o ensino da arte e sua história (1989, São Paulo). O Ensino da Arte e sua História. São Paulo: MAC/USP, 1990.

Texto recebido em 12 de novembro de 2018.

Texto aprovado em 14 de dezembro de 2018. 